\title{
Participatory Action Research in Software Development: Indigenous Knowledge Management Systems Case Study
}

\author{
Siang-Ting Siew ${ }^{1}$, Alvin W. Yeo ${ }^{2}$, and Tariq Zaman ${ }^{2}$ \\ ${ }^{1}$ Faculty of Computer Science and Information Technology \\ ${ }^{2}$ Institute of Social Informatics and Technological Innovations \\ Universiti Malaysia Sarawak (UNIMAS) \\ \{s.siangting, zamantariq\} egmail.com, \\ alvin@isiti.unimas.my
}

\begin{abstract}
Participatory action Research In Software Methodology Augmentation (PRISMA) is a software development methodology which has been amalgamated with Participatory Action Research (PAR). This paper justifies the inclusion of PAR in software development, and describes the PRISMA methodology vis-à-vis a case study. Specifically, the case study encompasses the development of eToro, an Indigenous Knowledge Management System for the Penans, a remote and rural community in Malaysian Borneo.
\end{abstract}

Keywords: Participatory Action Research, Software Development, PRISMA, Penans, Indigenous Botanical Knowledge Management, Remote Malaysian Borneo.

\section{ICTs for the Underserved}

It is generally acknowledged that providing Information and Communication Technologies (ICTs) to remote and rural communities can help in alleviating poverty and/or improving the socio-economic status of the communities. Among the many benefits of providing ICTs include giving access to unlimited knowledge (e.g. elearning), providing health-related services (telediagnosis), offering businesses opportunities (e-commerce), employment opportunities, and access to government services (e-Government websites) [1]. Evidence suggests that rural dwellers have more to gain than urban dwellers from any increase in the density of communications capability [2], but the absence of relevant experience, local content and skills are major barriers for rural ICT usage $[3,4]$.

Of importance is the need to build good quality and relevant ICTs (software included) which addresses the communities' needs. The local communities have their own concepts of knowledge and forms of communicating. As such, it is necessary that they should be able to use ICTs in such a way that their cultural identity is not compromised [5]. Furthermore, to prevent irrelevant "alien" conceptualizations from being carried forward into the implementation, the design and evaluation process need to be fully appropriated by the user community [6]. 